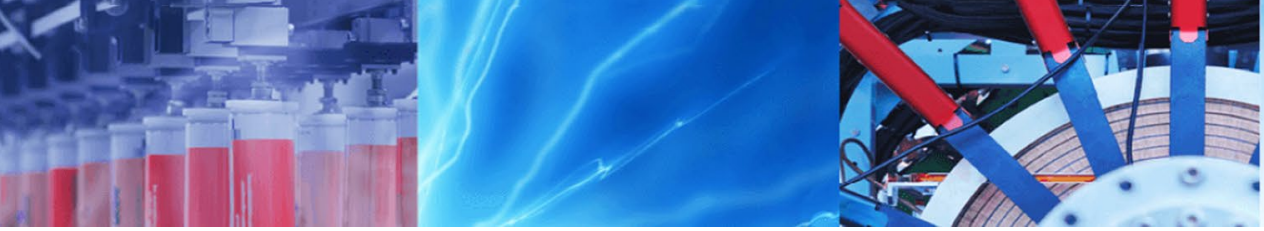

Research Article

\title{
Optimisation and effect of tool rake and approach angle on surface roughness and cutting tool vibration
}

\author{
J. Ashish George ${ }^{1}$ DD $\cdot$ K. Lokesha ${ }^{1}$
}

(c) Springer Nature Switzerland AG 2019

\begin{abstract}
Over the years, machining has been one of the pivotal manufacturing processes used in industries to produce superior products where multiple aspects regulate their efficacy. In this work, the motive is to study the effect of tool rake and approach angle in turning of mild steel specimens while varying process parameters such as spindle speed, feed rate and depth of cut. Experiments were designed using Taguchi $L_{9}$ orthogonal array. For every trail, cutting tool vibrations were recorded using tri-axial accelerometer connected to a fast Fourier transform analyser after which surface roughness tests were conducted. Analysis of variance was performed to obtain significant parameters. Results revealed that spindle speed and feed rate predominantly affect surface roughness with approach angle contributing certain level of influence. Spindle speed highly influences vibrations in the tangential and radial direction while depth of cut and rake angle have significant effect on vibrations in the axial direction.
\end{abstract}

Keywords Accelerometer · ANOVA · Optimisation · Surface roughness · Taguchi · Vibrations

\section{Introduction}

Machining is a term used to describe a variety of material removal processes where a cutting tool removes unwanted material from workpiece to produce the desired shape. While machined parts are mostly metallic in nature, almost all materials can be machined, including plastics, composites and wood, making it the most common and versatile of all manufacturing processes. In turning operation, layers of material are removed from a rotating workpiece with the aid of a single-point cutting tool [1]. Quality of the finished component is the essence of satisfaction which is influenced by process parameters that manipulate response parameter [2], thereby requiring an optimised combination of cutting parameters.

Ranganath et al. [3] aimed to investigate the effect of rake angle on surface roughness in CNC turning of Al 6061 by varying three positive rake angles. Analysis of variance (ANOVA) revealed that surface roughness decreases with the increase in rake angle. Karim et al. [4] presented their work that proposes the study of surface finish by varying three tool rake angles in the positive and negative scale during machining of $\mathrm{Al} 6061$ and observed that higher the rake angle used, better the surface finish generated. The effect of approach angle and nose radius on surface finish of $\mathrm{Ni}-\mathrm{Cr}$-Fe-based Inconel 718 super alloy was studied by Kumar et al. [5]. They concluded by way of analysis of variance that tool nose radius was effective in altering surface quality. Yaldiz et al. [6] studied the application of response surface methodology on turning of AISI 1040 steel by varying three levels of tool nose radius, approach angle and rake angle. It was observed that nose radius significantly affected surface roughness while approach and rake angle contributed almost similar influence on the same. Hard turning of AISI 52100 with ceramic cutting tools was performed by Boy et al. [7] to study the effect of approach angle on cutting forces and surface roughness. Based

$\bowtie$ J. Ashish George, ashish.georgej@gmail.com | 'Department of Mechanical Engineering, M S Ramaiah Institute of Technology, Bengaluru, India.

SN Applied Sciences (2019) 1:1133 | https://doi.org/10.1007/s42452-019-1175-z

Received: 21 May 2019 / Accepted: 28 August 2019 / Published online: 31 August 2019 
on ANOVA results, they concluded that cutting forces decrease with the increase in approach angle.

The effect of spindle speed and depth of cut on tool vibration was examined by Singh et al. [8] where dry turning was performed on mild steel, aluminium and PVC. Khoshnaw et al. [9] presented study based on the influence of tool vibration on surface roughness in dry turning which reveals that there is significant proportional effect. Comparison of optimising machining parameters for improved surface roughness between full factorial and Taguchi method was carried out by Athreya et al. [10].

Experiments were conducted on AISI steel on CNC lathe by Rao et al. [11] to describe the influence of process parameters on surface roughness where analysis of variances indicated that feed rate is exceptionally significant. Kaladhar et al. [12] performed turning experiments on stainless steel by varying tool cutting factors to analyse surface roughness where it was determined that feed rate influences remarkably. Aherwar [13] conducted experimentation based on Taguchi $\mathrm{L}_{9}$ orthogonal array to determine tool vibrations during turning of EN24 steel. Results revealed that axial vibration is less compared to tangential vibration. Effect of process parameters on surface roughness was studied by Makadia et al. [14] on full factorial DOE by performing ANOVA only to reveal that feed rate is most influential followed by tool nose radius.

Influence of tool rake angle on cutting vibration at different cutting speeds was investigated by Wang et al. [15] where it was inferred that the amplitude of machining vibration gradually decreases with increasing rake angle. Kannan et al. [16] conducted research work aimed at studying the effect of tool nose radius on tool chatter in the turning of EN19 steel where vibrational frequencies were captured by vibration absorber. Results showed that frequencies intensified with the increase in nose radius. Different controlled factors encapsulating single-point cutting tool were studied by Patil et al. [17] based on vibration amplitude where comparison of carbide and HSS tools was done only to show that the former generated lesser vibrations and produced better surface finish. Abdulhani et al. [18] presented his research work on the study of vibration relating to faults in turning centre $\mathrm{CNC}$ machine using FFT analyser by machining aluminium and mild steel specimens. It was concluded that the type of material directly influences vibrations, with axial vibration being the largest. Gandhi [19] carried out tests on a HMT lathe using four different rake angled tools to determine the vibration levels using FFT analyser. With workpiece material as mild steel, it was indicated that larger rake angle increases the stability of vibration.

During turning, various cutting forces tend to be developed which in turn generate vibrations in different directions. Gunay et al. [20] investigated the influence of tool rake angle on main cutting force which was measured using eight different rake angles and observed a decreasing cutting force trend with increasing rake angle. Magdum [21] studied the effect of cutting forces generated in the turning of EN 8 steel while varying the approach angle and revealed that thrust force decreased while feed force increased with the increase in approach angle. Rafeeq et al. [22] focussed on optimisation of feed and radial forces with respect to input parameters while machining EN321B steel. They concluded that high cutting speed and low feed generate lower forces.

In concordance with the research reviewed, the basic purpose of this work is to study the combined effect of tool geometry (rake angle and approach angle) and machining parameters (spindle speed, feed rate and depth of cut) on surface roughness and cutting tool vibration. Taguchi design of experiments [23] was employed to cultivate a suitable relation between the parameters since the objective is to determine the right settings [24]. Significance of parameters was depicted by analysis of variance, and optimal levels of parameters were determined using Taguchi signal-to-noise ratio technique.

\section{Experimental details}

The workpiece material selected for this study was mild steel whose chemical composition is shown in Table 1. Each test specimen, of hardness value $197 \mathrm{BHN}$, was dimensioned at $20 \mathrm{~mm}$ diameter and $200 \mathrm{~mm}$ length. Three tungsten carbide tool inserts having positive rake angles $0^{\circ}, 6^{\circ}$ and $9^{\circ}$ were utilised for performing turning operations. The general nomenclature for each of the inserts is CCMT 09T304 with variation only in the chipbreaker designation. In the increasing value of rake angles, these inserts have their designations as MT, FA and FG, respectively. Tool holder with nomenclature SCLCR $1616 \mathrm{H} 09$ was selected to mount the tool inserts. The experiments were carried out on HMT LT20 precision centre lathe.

The approach angles selected in this study were $75^{\circ}$, $80^{\circ}$ and $90^{\circ}$. These angles were achieved by swivelling the degree graduated compound rest, such that the tool
Table 1 Chemical composition of mild steel (wt\%)

\section{SN Applied Sciences}

\begin{tabular}{llllllll}
\hline $\mathrm{C}$ & $\mathrm{Si}$ & $\mathrm{Mn}$ & $\mathrm{Mo}$ & $\mathrm{P}$ & $\mathrm{Ni}$ & $\mathrm{S}$ & $\mathrm{Cr}$ \\
\hline 0.244 & 0.208 & 0.639 & 0.011 & 0.047 & 0.029 & 0.031 & 0.076 \\
\hline
\end{tabular}




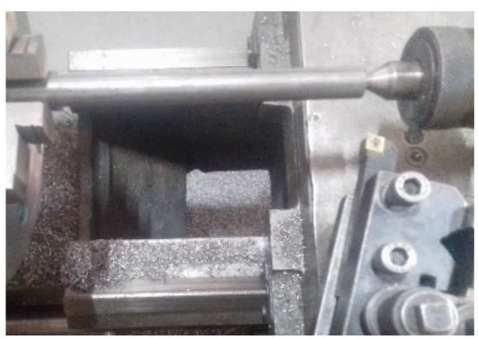

Approach angle $75^{\circ}$

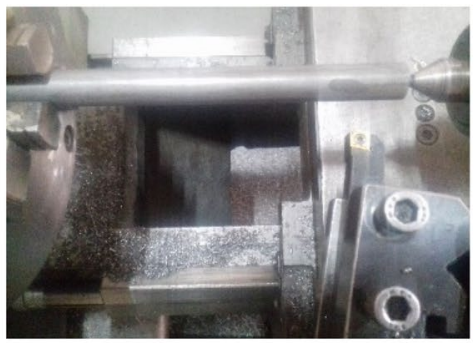

Approach angle $80^{\circ}$

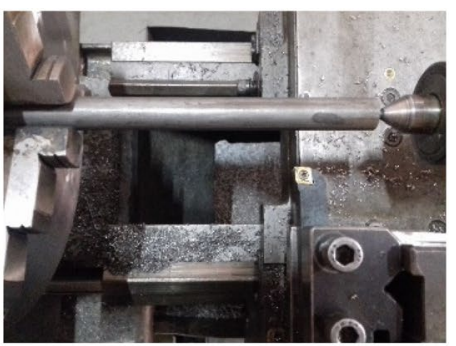

Approach angle $90^{\circ}$

Fig. 1 Experimental arrangement for different approach angles

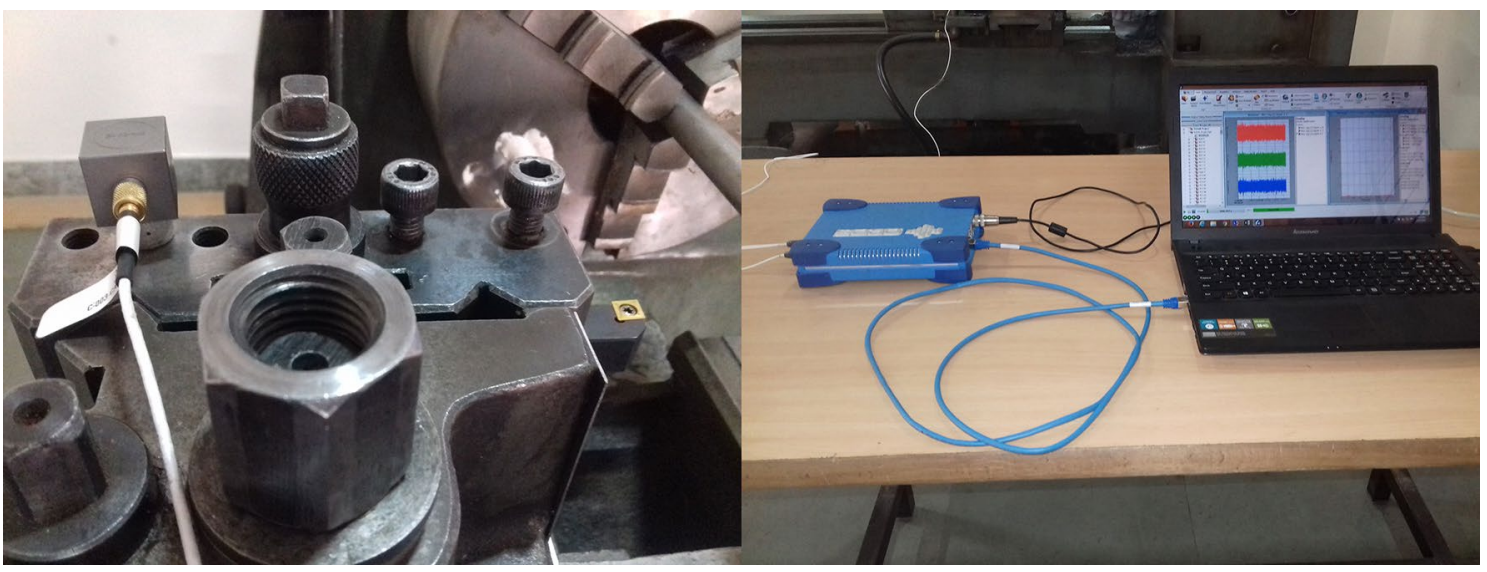

Fig. 2 Vibration measurement setup

Table 2 Input parameters and their levels

\begin{tabular}{llllll}
\hline Levels & $\begin{array}{l}\text { Spindle } \\
\text { speed, } n, \\
\text { rpm }\end{array}$ & $\begin{array}{l}\text { Feed rate, } \\
f, \mathrm{~mm} / \mathrm{rev}\end{array}$ & $\begin{array}{l}\text { Depth of } \\
\text { cut, } d, \mathrm{~mm}\end{array}$ & $\begin{array}{l}\text { Rake } \\
\text { angle, } \\
\gamma_{r}{ }^{\circ}\end{array}$ & $\begin{array}{l}\text { Approach } \\
\text { angle, } a^{\circ}\end{array}$ \\
\hline 1 & 420 & 0.05 & 0.25 & 0 & 75 \\
2 & 710 & 0.11 & 0.50 & 6 & 80 \\
3 & 1200 & 0.22 & 0.75 & 9 & 90 \\
\hline
\end{tabular}

post can be positioned at the desired angles. Therefore, movement of the carriage in the feed direction will cause the cutting tool to be fed at the set angle. Figure 1 shows the photographs of the tool inserts at different approach angles. Tri-axial accelerometer was mounted on the tool post and connected to the input of FFT analyser which served as the means of vibration measurement (Fig. 2). Post-turning operations and surface roughness of specimens were measured with the help of Mitutoyo SJ-201 surface roughness instrument whose sampling length is $2.5 \mathrm{~mm}$. The levels of input parameters chosen for this study are shown in Table 2.
The experiments were designed based on Taguchi $L_{9}$ orthogonal array which exhibits the combination of spindle speed, feed rate, depth of cut and rake angle as the standard $\mathrm{L}_{9}$ design, being implemented for each approach angle, thereby computing a total of 27 experiments for conduction. Tabulated data include recorded values of tool chatter in the three axes ( $X$-, $Y$ - and $Z$-axis) and surface roughness $(R a)$ for each experimental run.

\section{Results and discussion}

Analysis of variance was conducted on the experimental data obtained to determine factors that have significant effect on the response parameters, i.e. tri-axial vibrations and surface roughness $R a$. The ANOVA tables for each response parameter exhibit the degrees of freedom $(d f)$, sum of squares (SS), mean of squares (MS), $F$-values, $P$ values and the percentage contribution ratio (PCR) for every factor. Confidence level for all intervals was taken as $95 \%$ with the type of confidence being two-sided. Minitab 18.0 software was used to perform the test since it has in-built ANOVA tool feature. The independent variables considered 
are the input process parameters while the dependent variables are surface roughness and tool chatter.

ANOVA results for surface roughness shown in Table 3 portray spindle speed to be the most influential parameter while feed rate also affects the same whose PCR values are $57.70 \%$ and $26.43 \%$, respectively. Figure 3 conveys that as spindle speed increases, $R a$ values tend to decrease, whereas it increases with the increase in feed rate. It can also be seen that as approach angle is reduced, roughness tends to lessen. Surface roughness mean variation with respect to parameters varies to a maximum at low spindle speed of $420 \mathrm{rpm}$, higher feed rate of $0.22 \mathrm{~mm} / \mathrm{rev}$, depth of cut at $0.25 \mathrm{~mm}$, tool rake angle of $0^{\circ}$ and approach angle of $90^{\circ}$.

The ANOVA results and mean effective plot for tool vibrations in the three directions (tangential, axial and radial) are discussed in the following segments.

Since $F$ and $P$ values are the ones that determine the significant parameters from ANOVA results, it can be seen from Table 4 that the most influential factor for tangential vibration is spindle speed contributing to $71.64 \%$ of the total effect, whereas the approach angle shows the least effect with PCR value of $1.02 \%$. The mean effective plots in Fig. 4 show the variation of the mean of
Table 3 ANOVA results for surface roughness

\begin{tabular}{lrrrrrr}
\hline Source & $d f$ & \multicolumn{1}{l}{ SS } & \multicolumn{1}{l}{ MS } & F-value & $P$ value & PCR \\
\hline$n$ & 2 & 48.9550 & 24.4775 & 38.49 & 0.000001 & 57.70 \\
$f$ & 2 & 22.4269 & 11.2135 & 17.63 & 0.000092 & 26.43 \\
$d$ & 2 & 1.2014 & 0.6007 & 0.94 & 0.409499 & 1.42 \\
$\gamma$ & 2 & 0.8148 & 0.4074 & 0.64 & 0.539948 & 0.96 \\
$a$ & 2 & 1.2695 & 0.6347 & 1.00 & 0.390410 & 1.50 \\
Error & 16 & 10.1752 & 0.6360 & & & 11.99 \\
Total & 26 & 84.8428 & & & & \\
\hline
\end{tabular}

Fig. 3 Mean effective plot for surface roughness
Table 4 ANOVA results for tangential vibration

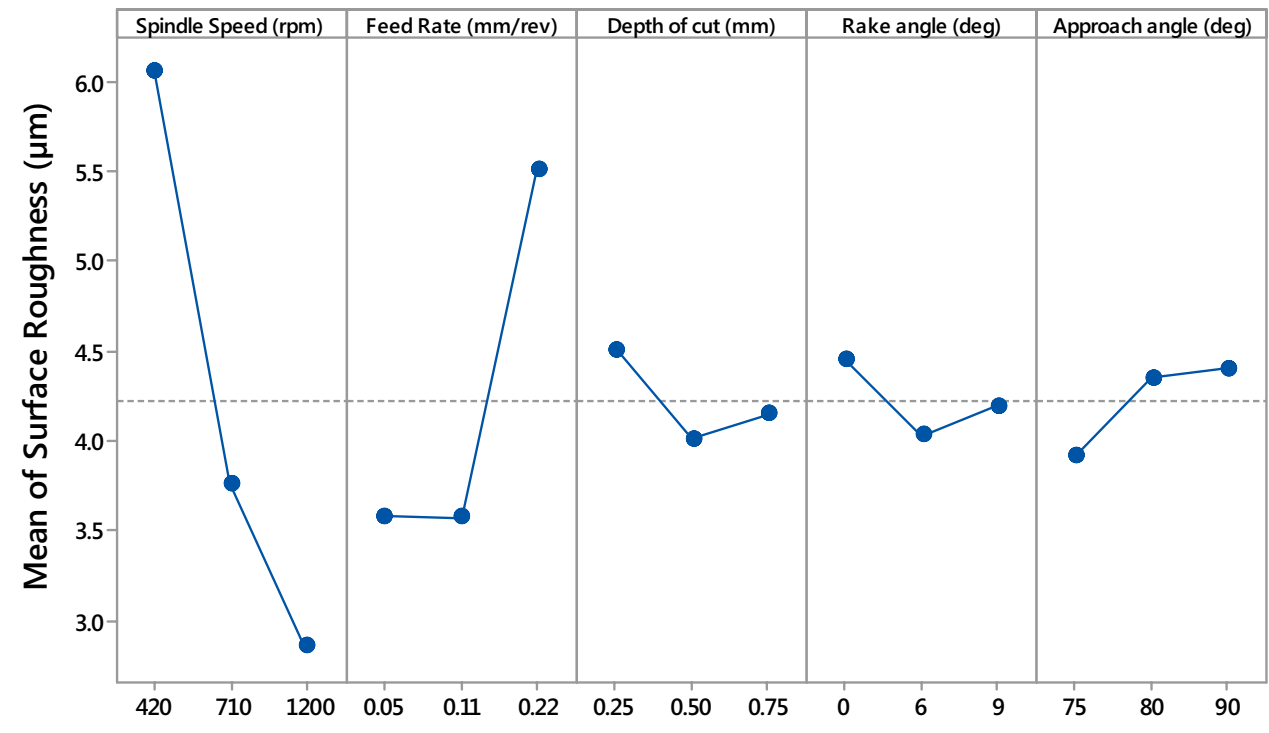

\begin{tabular}{lrrrrrr}
\hline Source & $d f$ & \multicolumn{1}{c}{ SS } & \multicolumn{1}{c}{ MS } & F-value & $P$ value & PCR \\
\hline$n$ & 2 & 50.5882 & 25.2941 & 38.88 & 0.000001 & 71.64 \\
$f$ & 2 & 2.2207 & 1.1104 & 1.71 & 0.212851 & 3.14 \\
$d$ & 2 & 5.7750 & 2.8875 & 4.44 & 0.029274 & 8.18 \\
$\gamma$ & 2 & 0.8992 & 0.4496 & 0.69 & 0.515359 & 1.27 \\
$a$ & 2 & 0.7200 & 0.3600 & 0.55 & 0.585598 & 1.02 \\
Error & 16 & 10.4081 & 0.6505 & & & 14.74 \\
Total & 26 & 70.6111 & & & & \\
\hline
\end{tabular}


Fig. 4 Mean effective plot for tangential vibration

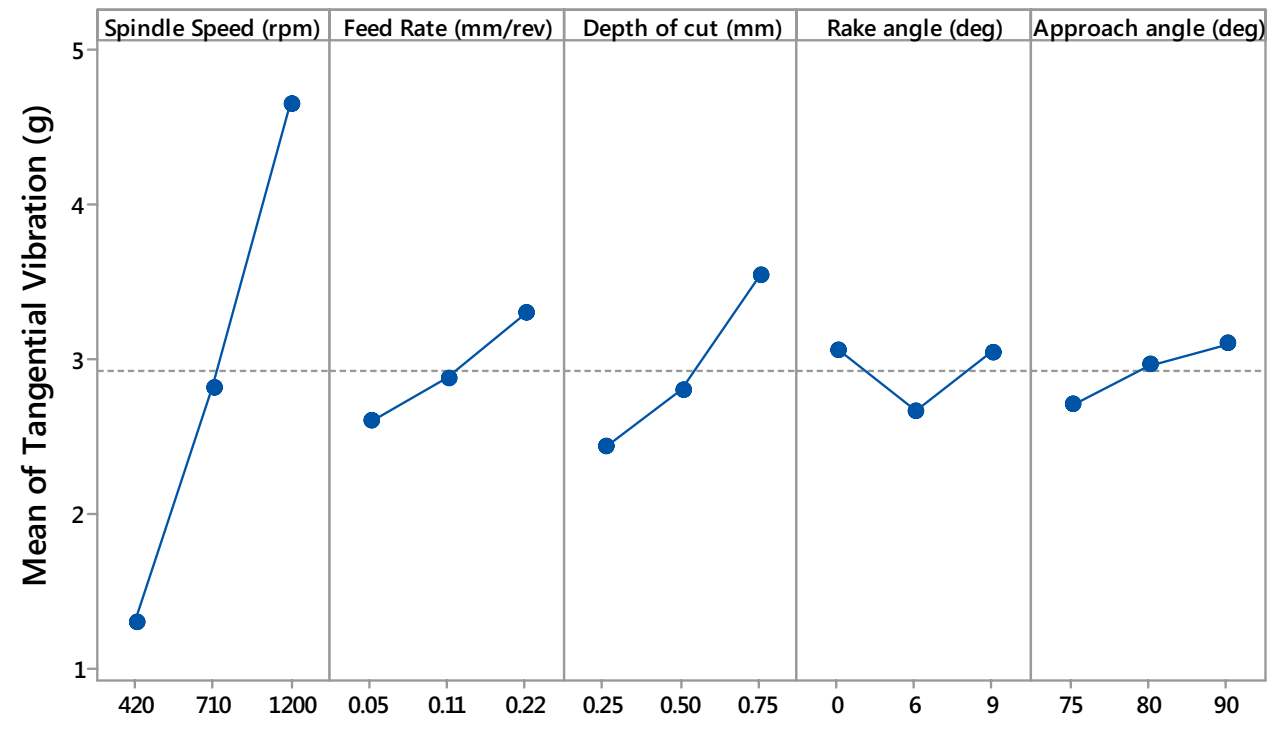

tangential vibration with respect to change in process parameters. According to the plots, it can be interpreted that with increasing spindle speed, feed rate and depth of cut values, vibrations in the tangential direction intensify. The vibration values are maximum at spindle speed of $1200 \mathrm{rpm}$, feed rate of $0.22 \mathrm{~mm} / \mathrm{rev}$, depth of cut of $0.75 \mathrm{~mm}$ and tool rake angle of $9^{\circ}$ with the tool approaching at $90^{\circ}$.

From the ANOVA results in Table 5 for axial vibration, it can be seen that the F-value for depth of cut is maximum, thus representing it to be the most significant parameter influencing vibrations in the axial direction with a contribution percentage of $51.36 \%$. It should be noted that tool rake angle and feed rate have a similar definitive level of significance, providing $8.00 \%$ and $8.43 \%$, respectively, of the total effect while approach angle does not considerably affect axial vibrations.

The variation in the mean of axial vibration with respect to the process parameters is shown in Fig. 5. The plots reveal that as depth of cut and spindle speed increase, greater are the vibrations developed. It is also worth noting that approaching the tool at an angle lesser than $90^{\circ}$ tends to produce more axial vibrations. The maximum mean values of vibration as depicted by the plot can be observed to occur at spindle speed of $1200 \mathrm{rpm}$, feed rate of $0.22 \mathrm{~mm} / \mathrm{rev}$ with depth of cut of $0.75 \mathrm{~mm}, 6^{\circ}$ tool rake angle and $75^{\circ}$ approach angle.

According to the ANOVA results for radial vibration shown in Table 6, it is evident that the depth of cut is the most influential factor which is closely followed by spindle speed as it also majorly affects the vibrations in radial direction. The percentage of contribution for both these parameters is $39.12 \%$ and $36.50 \%$, respectively. The mean effective plot in Fig. 6 shows the variation of the mean of radial vibration with respect to change in the levels of process parameters. With every increasing value of spindle speed and depth of cut, vibrations in the radial direction are observed to be developed substantially. Also, these vibrations are seen to be grown when tool rake angle is changed from $0^{\circ}$ to $9^{\circ}$. As for approach angle, radial vibrations seem to have a reducing trend when the tool is positioned from $75^{\circ}$ to $90^{\circ}$. The maximum mean values of vibration as depicted by the plot can be observed to occur at spindle speed of $1200 \mathrm{rpm}$, feed rate of $0.22 \mathrm{~mm} /$ rev with a depth of cut of $0.75 \mathrm{~mm}$, tool rake angle of $9^{\circ}$ and approach angle of $80^{\circ}$.

Based on the values recorded for every experimental run, it was observed that vibrations in the tangential

Table 5 ANOVA results for axial vibration

\begin{tabular}{lrrlrrr}
\hline Source & $d f$ & \multicolumn{1}{c}{ SS } & MS & F-value & $P$ value & PCR \\
\hline$n$ & 2 & 1.1599 & 0.5799 & 1.29 & 0.301368 & 4.46 \\
$f$ & 2 & 2.1911 & 1.0955 & 2.44 & 0.118487 & 8.43 \\
$d$ & 2 & 13.3515 & 6.6757 & 14.89 & 0.000222 & 51.36 \\
$\gamma$ & 2 & 2.0758 & 1.0393 & 2.32 & 0.130522 & 8.00 \\
$a$ & 2 & 0.0423 & 0.0211 & 0.05 & 0.954083 & 0.16 \\
Error & 16 & 7.1710 & 0.4482 & & & 27.59 \\
Total & 26 & 25.9943 & & & & \\
\hline
\end{tabular}


Fig. 5 Mean effective plot for axial vibration

Table 6 ANOVA results for radial vibration

Fig. 6 Mean effective plot for radial vibration

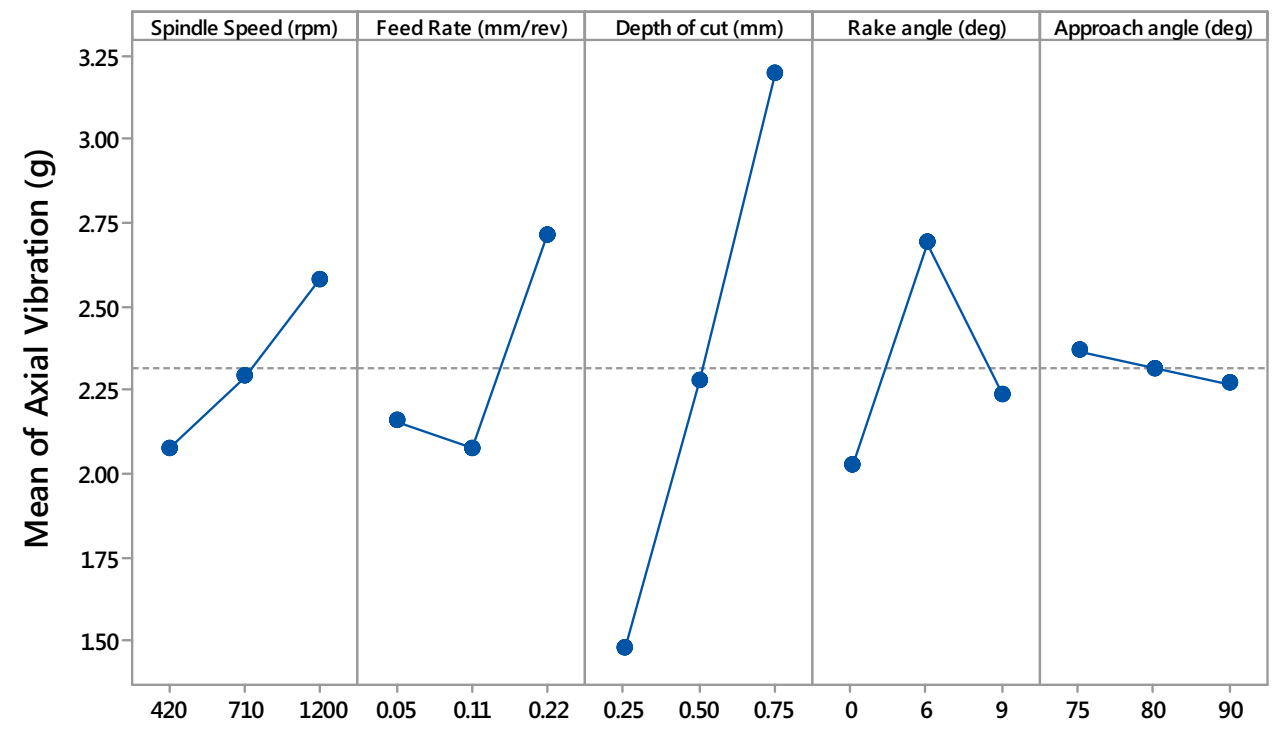

\begin{tabular}{lrrlrrr}
\hline Source & $d f$ & \multicolumn{1}{l}{ SS } & MS & F-value & $P$ value & PCR \\
\hline$n$ & 2 & 8.2771 & 4.1368 & 17.72 & 0.000088 & 36.50 \\
$f$ & 2 & 1.2332 & 0.6166 & 2.64 & 0.102136 & 5.44 \\
$d$ & 2 & 8.8709 & 4.4354 & 18.99 & 0.000060 & 39.12 \\
$\gamma$ & 2 & 0.3344 & 0.1672 & 0.72 & 0.503786 & 1.47 \\
$a$ & 2 & 0.2228 & 0.1114 & 0.48 & 0.629206 & 0.98 \\
Error & 16 & 3.7369 & 0.2336 & & & 16.48 \\
Total & 26 & 22.6753 & & & & \\
\hline
\end{tabular}

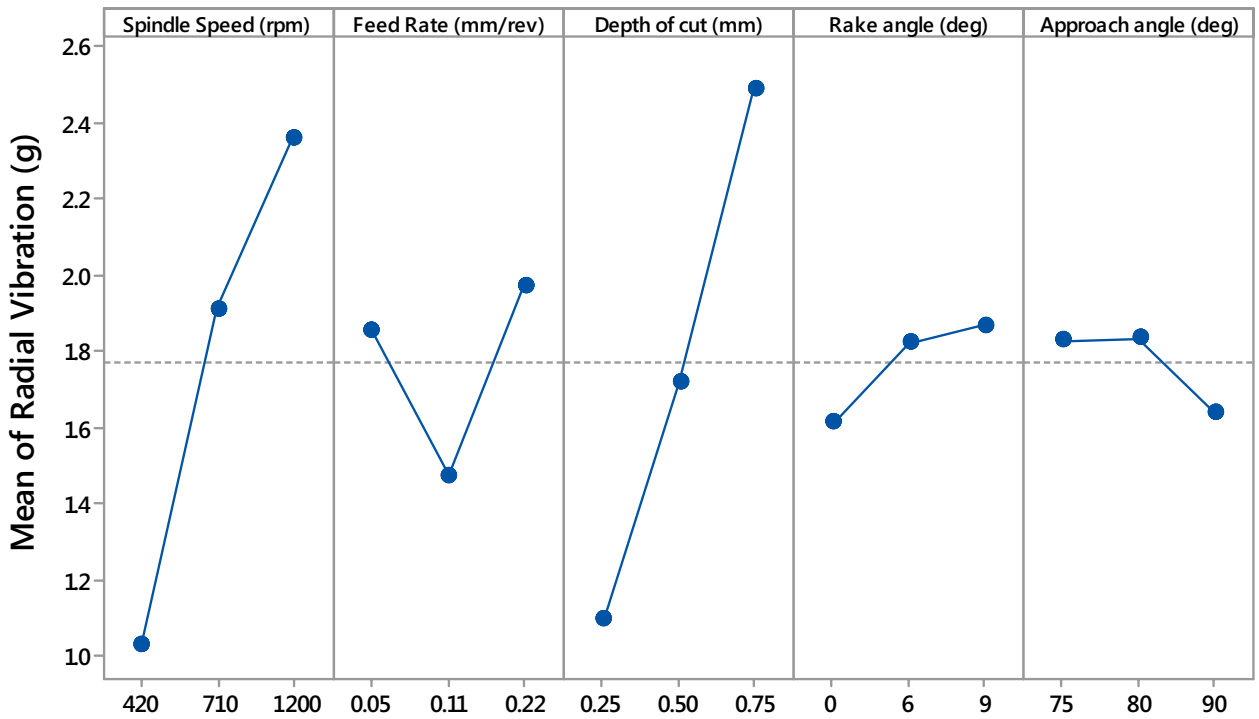

direction were considerably greater compared to the other directions. Measured surface roughness values showed a declining trend when minimum feed rate and depth of cut were maintained while increasing spindle speed and rake angle and with the tool approach angle being reduced from $90^{\circ}$ to $75^{\circ}$.

It should be noted that the values for the source of error in the ANOVA results tabulated have considerable 
magnitude. The reason is that there could be different interaction effects between the control factors for each of the response parameter being considered in this study. Since the present work primarily draws attention towards the main effect of process parameters, the effects of interaction could be conducted in another study for a full factorial set of experiments as this type of design is more suited for interaction cases [25].

\section{Optimisation of process parameters}

For performing any operation in the most feasible manner possible, it is required to have knowledge of the optimal levels of the parameters being considered. In this present work, Taguchi method of deriving optimal parameters is utilised by generating the smaller the better type of signalto-noise $(S / N)$ ratios [26] to determine the ideal levels of parameters.

$S / N=-10 \log \left(\frac{1}{n} \sum_{i=1}^{n} Y_{i}^{2}\right)$

where $Y_{i}$ is the determined value of the characteristic response at the $i$ th experiment for $n$ number of experiments.

Smaller the better technique has been chosen for the purpose of study since the aim of this work is to minimise the characteristic response [27], i.e. tool vibrations and surface roughness based on the input parameters selected and to yield the optimal level of each parameter thus promoting favourable machining conditions.

This technique indicates optimal levels of parameters by evaluating the $S / N$ ratios corresponding to each level and judging its nearness to the value zero. With emphasis on this statement, it can be concluded, from the response table of $S / N$ ratios shown in Table 7, that the optimal levels for surface roughness are $1200 \mathrm{rpm}$ of spindle speed, $0.05 \mathrm{~mm} / \mathrm{rev}$ of feed rate, $0.50 \mathrm{~mm}$ depth of cut, $9^{\circ}$ tool rake angle and $75^{\circ}$ tool approach angle. Based on the results obtained, it can be interpreted that with a high value of spindle speed, rake angle along with minimum

Table 7 Response table of $S / N$ ratios for surface roughness

\begin{tabular}{llllll}
\hline Level & $n(\mathrm{rpm})$ & $\mathrm{f}(\mathrm{mm} / \mathrm{rev})$ & $d(\mathrm{~mm})$ & $\gamma\left(^{\circ}\right)$ & $a\left(^{\circ}\right)$ \\
\hline 1 & -15.452 & $-\mathbf{1 0 . 2 0 3}$ & -12.166 & -12.226 & $-\mathbf{1 0 . 4 6 1}$ \\
2 & -10.993 & -10.323 & $-\mathbf{1 1 . 2 8 8}$ & -11.526 & -12.569 \\
3 & $-\mathbf{8 . 6 3 6}$ & -14.555 & -11.626 & $-\mathbf{1 1 . 4 1 9}$ & -11.391 \\
Delta & 6.816 & 4.352 & 0.877 & 0.717 & 2.108 \\
Rank & 1 & 2 & 4 & 5 & 3 \\
\hline
\end{tabular}

feed rate, depth of cut and smaller approach angle, better surface finished components can be manufactured.

The $S / N$ ratio response table for tangential vibration shown in Table 8 depicts the optimal levels of process parameters. Spindle speed is the most influential parameter with $420 \mathrm{rpm}$ as the optimal level and is followed by depth of cut whose optimal level is $0.25 \mathrm{~mm}$. The optimal levels for the other parameters are $0.05 \mathrm{~mm} / \mathrm{rev}$ of feed rate, $6^{\circ}$ tool rake angle and $80^{\circ}$ tool approach angle. Fewer vibrations are developed in tangential direction when the levels of process parameters are within minimum range while the tool is mounted at an angle slightly less than $90^{\circ}$.

From the response table shown in Table 9, it can be observed that depth of cut influences axial vibration the most and its optimal level is $0.25 \mathrm{~mm}$. The next influential parameter is tool rake angle with optimal level of $0^{\circ}$ while spindle speed follows it with an optimal level of $420 \mathrm{rpm}$. The other parameters having optimal levels are $0.05 \mathrm{~mm} /$ rev feed rate and $90^{\circ}$ tool approach angle. The results show that minimum levels of process parameters, with the tool positioned conventionally, produce lesser vibrations in the axial direction.

Based on the rank of process parameters from the response table displayed in Table 10, it can be said that spindle speed influences radial vibration the most, followed by depth of cut and feed rate. The optimal levels for each of the selected parameters are $420 \mathrm{rpm}$ of spindle speed, $0.11 \mathrm{~mm} / \mathrm{rev}$ feed rate, $0.25 \mathrm{~mm}$ depth of cut, $0^{\circ}$ tool rake angle and $90^{\circ}$ approach angle. Smaller values of spindle speed, depth of cut and tool rake angle with the tool placed traditionally at $90^{\circ}$ generates lesser vibrations in the radial direction.

Table 8 Response table of $S / N$ ratios for tangential vibration

\begin{tabular}{llllll}
\hline Level & $n(\mathrm{rpm})$ & $f(\mathrm{~mm} / \mathrm{rev})$ & $d(\mathrm{~mm})$ & $\gamma\left(^{\circ}\right)$ & $a\left(^{\circ}\right)$ \\
\hline 1 & $-\mathbf{1 . 9 6 7}$ & $-\mathbf{6 . 9 0 2}$ & $-\mathbf{6 . 1 7 5}$ & -8.430 & -7.777 \\
2 & -8.291 & -7.359 & -7.689 & $-\mathbf{6 . 4 8 8}$ & $-\mathbf{7 . 4 6 8}$ \\
3 & -13.191 & -9.191 & -9.584 & -8.530 & -8.204 \\
Delta & 11.224 & 2.289 & 3.409 & 2.042 & 0.736 \\
Rank & 1 & 3 & 2 & 4 & 5 \\
\hline
\end{tabular}

Table 9 Response table of $S / N$ ratios for axial vibration

\begin{tabular}{llllll}
\hline Level & $n(\mathrm{rpm})$ & $f(\mathrm{~mm} / \mathrm{rev})$ & $d(\mathrm{~mm})$ & $\gamma\left(^{\circ}\right)$ & $a\left(^{\circ}\right)$ \\
\hline 1 & $-\mathbf{5 . 4 4 2}$ & $\mathbf{- 5 . 8 1 1}$ & $-\mathbf{3 . 0 8 0}$ & $-\mathbf{5 . 6 3 1}$ & -6.752 \\
2 & -6.625 & -6.063 & -6.848 & -7.887 & -7.013 \\
3 & -7.577 & -7.770 & -9.716 & -6.126 & $-\mathbf{5 . 8 7 9}$ \\
Delta & 2.135 & 1.959 & 6.636 & 2.256 & 1.134 \\
Rank & 3 & 4 & 1 & 2 & 5 \\
\hline
\end{tabular}


Table 10 Response table of $S / N$ ratios for radial vibration

\begin{tabular}{llllll}
\hline Level & $n(\mathrm{rpm})$ & $f(\mathrm{~mm} / \mathrm{rev})$ & $d(\mathrm{~mm})$ & $\gamma\left(^{\circ}\right)$ & $a\left(^{\circ}\right)$ \\
\hline 1 & $\mathbf{0 . 3 2 7 8}$ & -3.5358 & $-\mathbf{0 . 2 0 0 3}$ & $-\mathbf{3 . 1 8 8 9}$ & -4.3889 \\
2 & -4.9114 & $-\mathbf{2 . 5 0 9 1}$ & -4.2374 & -3.7896 & -3.9174 \\
3 & -6.8290 & -5.3677 & -6.9750 & -4.4340 & $-\mathbf{3 . 1 0 6 3}$ \\
Delta & 7.1568 & 2.8586 & 6.7747 & 1.2451 & 1.2827 \\
Rank & 1 & 3 & 2 & 5 & 4 \\
\hline
\end{tabular}

\section{Conclusions}

The present study illustrates the influence of process parameters and tool geometry in turning operation by considering surface roughness and tool vibration as the response objective. Experiments were carried out on mild steel specimen based on Taguchi $L_{9}$ orthogonal array for which tool chatter and surface roughness were recorded and measured, respectively. The findings that can be condensed from this study are as follows:

Spindle speed and feed rate largely affect surface roughness with tool approach angle having comparatively more influence than rake angle. Spindle speed also majorly affects tangential vibration while tool approach and rake angle have almost similar impact on the same.

Depth of cut and tool rake angle have a substantial contribution for vibrations in the axial direction, but approach angle has negligible effect. Radial vibration is mainly influenced by spindle speed and depth of cut while tool rake and approach angle have nearly the same involvement towards affecting this parameter.

The optimal conditions for surface roughness are observed at $n 3-f 1-d 2-\gamma 3-\alpha 1$ (spindle speed $=1200 \mathrm{rpm}$, feed rate $=0.05 \mathrm{~mm} / \mathrm{rev}$, depth of cut $=0.50 \mathrm{~mm}$, rake angle $=9^{\circ}$ and approach angle $=75^{\circ}$ ). Optimal conditions of turning parameters for tangential and axial vibration are inferred at $n 1-f 1-d 1-\gamma 2-a 2$ (spindle speed $=420 \mathrm{rpm}$, feed rate $=0.05 \mathrm{~mm} / \mathrm{rev}$, depth of cut $=0.25 \mathrm{~mm}$, rake angle $=6^{\circ}$ and approach angle $=75^{\circ}$ ) and $n 1-f 1-d 1$ $\gamma 1-a 3$ (spindle speed $=420 \mathrm{rpm}$, feed rate $=0.05 \mathrm{~mm} / \mathrm{rev}$, depth of cut $=0.25 \mathrm{~mm}$, rake angle $=0^{\circ}$ and approach angle $=90^{\circ}$ ), respectively. For radial vibration, the optimal instances are obtained at $n 1-f 2-d 1-\gamma 1-a 3$ (spindle speed $=420 \mathrm{rpm}$, feed rate $=0.10 \mathrm{~mm} / \mathrm{rev}$, depth of cut $=0.25 \mathrm{~mm}$, rake angle $=0^{\circ}$ and approach angle $=90^{\circ}$ ).

Acknowledgements The authors gratefully thank the Department of Mechanical Engineering, M S Ramaiah Institute of Technology, Bengaluru, India, for providing their constant support to complete this work.

\section{Compliance with ethical standards}

Conflict of interest The authors are in complete agreement stating that there is no conflict of interest.

\section{References}

1. Lazarevic D, Madic M, Jankovic P, Lazarevic A (2012) Cutting parameters optimization for surface roughness in turning of polyethylene using Taguchi method. Tribol Ind 34(2):68-73

2. Tamizharasan T, Senthil Kumar N (2012) Analysis of surface roughness and material removal rate in turning using Taguchi's technique. In: IEEE-International conference on advance in engineering, science and management, pp 231-238

3. Ranganath MS, Vipin (2014) Effect of rake angle on surface roughness in CNC turning. Int J Adv Res Innov 2(2):522-530

4. Karim Z, Azuan SA, Yasir AM (2013) A Study on tool wear and surface finish by applying positive and negative rake angle during machining. Aust J Basic Appl Sci 7(10):46-51

5. Kumar S, Singh D, Kalsi N (2019) Investigating the effect of approach angle and nose radius on surface quality of Inconel 718. J Inst Eng (India) Ser C 100(1):121-128

6. Neseli S, Yaldiz S, Turkes E (2010) Optimisation of tool geometry parameters for turning operations based on the response surface methodology. Measurement 44:580-587

7. Boy M, Gunay M, Demir H, Ciftci I (2014) Effects of the approach angle on the cutting force and surface roughness on hard turning of AISI 52100. In: Proceedings of 19th international conference, Mechanika, pp 58-63

8. Singh JK, Bhardwaj SK (2015) Optimization of the cutting parameters by vibration analysis of cutting tool. Int J Latest Trends Eng Technol 5(1):270-275

9. Khoshnaw KY, Kassab YS (2007) The effect of cutting vibration on surface roughness of workpiece in dry turning operation. Eng Technol 25(7):879-889

10. Athreya S, Venkatesh YD (2012) Application of Taguchi method for optimization of process parameters in improving the surface roughness of lathe facing operation. Int Ref J Eng Sci 1(3):13-19

11. Rao CJ, Rao DN, Srihari $P$ (2013) Influence of cutting parameters on cutting force and surface finish in turning operation. Procedia Eng 64:1405-1415

12. Kaladhar M, Subbaiah KV, Srinivas Rao Ch, Narayana Rao K (2010) Optimisation of process parameters in turning of AISI202 austenitic stainless steel. J Eng Appl Sci 5(9):79-87

13. Aherwar A, Unune D, Pathri B, Krishan J (2014) Statistical and regression analysis of vibration of carbon steel cutting tool for turning of EN24 steel using design of experiments. Int J Recent Adv Mech Eng 3(3):172-181

14. Makadia JA, Nanavati IJ (2013) Optimisation of machining parameters for turning operations based on response surface methodology. Measurement 46:1521-1529

15. Wang GC, Ma LJ, Pei HJ (2014) Study on the effect of tool rake angle on cutting tool vibration in precision machining. Mater Sci Forum 471:127-131

16. Kanna CR, Paul AL (2017) Investigate the effect of tool nose radius on tool chatter in metal cutting process. Int J Adv Res Basic Eng Sci Technol 3(39):116-123

17. Patil AM, Patil IP, Patil T, Sonmale S (2018) Vibration analysis of single point cutting tool on lathe machine by using FFT analyser. Int J Innov Res Sci Eng Technol 7(9):9638-9645

18. Abdulhani F, ALswede J (2014) Study of vibration For CNC machine at difference feed. Int J Adv Res Technol 3(11):21-29 
19. Gandhi NB (2012) FFT based evaluation of cutting forces and chatter vibrations in turning by varing speed, feed, depth of cut and rake angle. GIT-J Eng Technol 5:1-4

20. Gunay M, Kotkut I, Aslan E, Seker U (2004) Experimental Investigation of the effect of cutting tool rake angle on main cutting force. J Mater Process Technol 16(6):44-49

21. Magdum VB (2016) Investigate the effect of approaching angle on cutting force during EN8 steel turning. Int J Comput Eng Res Trends 3(9):471-475

22. Rafeeq M, Kirmani MM (2014) Optimizing feed and radial forces on conventional lathe machine of EN31B Alloy steel through Taguchi's parameter design approach. Int J Eng Res Appl 4(4):134-144

23. Prasath KM, Pradheep T, Suresh S (2018) application of Taguchi and response surface methodology (RSM) in steel turning process to improve surface roughness and material removal rate. Mater Today Proc 5(11):24622-24631

24. Moayyedian M, Derakshandeh JF, Said S (2018) Experimental investigations of significant parameters of strain measurement employing Taguchi method. SN Appl Sci 1(1):92
25. Wang S, Huang GH (2014) A multi-level Taguchi-factorial twostage stochastic programming approach for characterization of parameters uncertainties and their interactions: an application to water resources management. Eur J Oper Res 240(2):572-581

26. Yurtkuran H, Korkmaz ME, Gunay M (2016) Modelling and optimisation of the surface roughness in high speed hard turning with coated and uncoated CBN insert. Gazi Univ J Sci 29(4):987-995

27. Boy M, Ciftci I, Gunay M, Ozhan F (2015) Application of the Taguchi method to optimize the cutting conditions in hard turning of a ring bore. Mater Technol 49(5):765-772

Publisher's Note Springer Nature remains neutral with regard to jurisdictional claims in published maps and institutional affiliations. 